\title{
Ocular Onchocerciasis
}

National Cancer Institute

\section{Source}

National Cancer Institute. Ocular Onchocerciasis. NCI Thesaurus. Code C34862.

Onchocerciasis affecting the eye. 